\title{
A qualitative study on integrated management systems in a non-leading country in
}

\section{certifications}

\begin{abstract}
The aim of this study is to analyze the integration of management systems in a country with low certifications number and growth rate and propose a research agenda towards improving the competitiveness of organizations that implement multiple management systems. The main research questions focuses on the implementation process itself and the effect of low level of national certification to the integration process. To serve this research purpose, an exploratory research is designed in Greece (a country with relatively low certification counts and rates to the ISO 9001 and ISO 14001 management standards). A case study approach is employed to enable deeper and comprehensive reasoning. A cross-case analysis is presented to explore patterns, similarities and differences among organizations. Findings show that 4 out of 5 organizations analyzed are integrating its management systems at different levels, the integration methodology applied is similar for all organizations but audits are the most dissimilar aspect. This study is one of the first that addresses management systems’ integration in Greece exploring contingency factors.
\end{abstract}

Keywords: Audits, Greece, integration of management systems, ISO 9001, ISO 14001.

\section{Introduction}

Over the past two decades, there was an enormous increase of management systems (MSs) standards certification, especially across Europe and Asia (see ISO, 2015). The most widespread international standards are those published by the International Organization for Standardization (ISO), specifically ISO 9001 for quality MSs (QMSs) and ISO 14001 for environmental MSs (EMSs). According to the most recent data worldwide, at the end of 2014, there were 1,138,155 certificates of ISO 9001 (an increase of 1\% from last year), and 324,148 certificates of ISO 14001 
(an increase of 7\% from last year). Other ISO MSs have also been widely implemented, such as the ISO 22000 food safety MS (an increase of 14\% from last year), ISO 50001 energy MS (an increase of 40\% from last year) and ISO 27001 information technology MSs (an increase of 7\% from last year). The main reasons and motives for ISO series implementation according to literature were: customer demand, increased competition, government regulations and cost reductions, among others (Gotzamani and Tsiotras, 2002; Williams, 2004; Casadesús and Karapetrovic, 2005; Karapetrovic et al., 2010).

Under these circumstances, an organization may have multiple MSs implemented and has the option to manage them either separately or in an integrated manner. The result of the latter possibility is an Integrated MS (IMS), that can be defined as a "set of interconnected processes that share a pool of human, information, material, infrastructure, and financial resources in order to achieve a composite of goals related to the satisfaction of a variety of stakeholders"' (Karapetrovic and Willborn, 1998a; Beckmerhagen et al., 2003a). Several studies on integration conclude that having an integrated MS in place entails increased efficiency and exploitation of synergies (Karapetrovic and Casadesús, 2009; López-Fresno, 2010; Zeng et al., 2011; Bernardo et al., 2012a, 2015; Botta et al., 2013).

Empirical research has focused mainly on the process of integration analyzing different aspects, including but not limited to the design and implementation of organization's integration strategy (Bernardo et al., 2012a; Mohannad et al., 2013), the integration methodology organizations use (Rebelo et al., 2014a, 2014b; Karapetrovic, 2005; Garengo and Biazzo, 2013; Kauppila et al., 2015), the current level of integration (Bernardo et al., 2009; Abad et al., 2014; Mezinska et al., 2015), and the integration of MSs' audits (Bernardo et al., 2010; Simon et al., 2014; Hoy and Foley, 2015). This research has been done, in majority, using surveys in those countries with a high level of certificates (Douglas and Glen, 2000; Bernardo et al., 2009; Abad et al., 2014; among others).

Taking all the above into account, the purpose of this research is to shift focus to a country that is ranked moderately low in terms of MS certifications. To this end, Greece is selected as the 
representative country being less advanced in terms of IMS research and ISO certifications compared to over-researched and high certification rated countries, such as Spain or UK. Five Greek case organizations are selected and analyzed qualitatively with respect to the main integration aspects, i.e., the integration strategy and methodology, the integration level and the integration of audits. Furthermore, IMS maintenance and evolution avenues are discussed and future research agenda is proposed to improve the competitiveness of the organizations via integrating their MSs. To better illustrate this research objectives the following research questions (RQ) are stated:

RQ1: How are the Greek organizations implementing the integration process?

RQ2: Is the low level of certifications having an impact on the process?

\section{Literature review}

In the literature, the process of integrating multiple MSs can be divided in four main aspects (see also Bernardo et al., 2012a; Domingues et al., 2015a), namely: a) integration strategy, b) integration methodology, c) integration level, and d) systems’ auditing integration.

The "integration strategy" refers to the scope and the implementation order. The most common strategies - in the case of the two most common MSs - based on Karapetrovic and Willborn (1998a), are to establish: first the QMS and second the EMS; first the EMS and second the QMS; and QMS and EMS simultaneously. In case of scope diversity, four strategies are identified (Karapetrovic, 2002a): first QMS then others; first EMS then others; simultaneous QMS and EMS then others and common IMS core then IMS modules. The existing empirical research supports these strategies and the majority of organizations is establishing first the QMS and second the EMS, mainly because of its chronological publication (Douglas and Glen, 2000; Labodová, 2004; Karapetrovic et al., 2006; Zeng et al., 2007; Griffith and Bhutto, 2008; Salomone, 2008; Karapetrovic and Casadesús, 2009; Mohannad et al., 2013). Bernardo et al. (2012a) argue that those 
organizations that implement QMS and EMS simultaneously achieve higher levels of integration, while those implementing more MSs and separately, achieve lower levels of integration.

The second aspect refers to the "methodology" or tools used in the integration process. This aspect is the least standardized although several proposals have been published. The integration methodology may be based either on a guideline published by a standardization body (AENOR, 2005; BSI, 2012) or on methodologies and frameworks proposed in the existing literature (Karapetrovic and Willborn, 1998a; Labodová, 2004; Karapetrovic, 2005; De Oliveira, 2013; Pal Pandi et al., 2016). For example, Karapetrovic et al. (2006) found that mostly used for integration was the process approach, because the majority of the organizations in the sample had implemented first the ISO 9001. Asif et al. (2009) present a methodology to achieve excellence in which the integration of MSs is a key step. Rebelo et al. (2014a, 2014b, 2016) also propose a model with the aim of improving the organizations' competitiveness, value added and sustainable success. Regarding this aspect, it has to be mentioned that ISO has not published an international standard for integration but it has published a manual giving advice and examples on the process (ISO, 2008) and is promoting integration through the High Level Structure (HLS), i.e., all the new and renewed MSs has the same structure and this is enhancing its integration.

The "degree of integration" is another major issue covered to a great extent in the IMS literature. There are different levels of integration defined in the literature (Karapetrovic, 2002a, 2003; Kirkby, 2002; Santos et al., 2011; Mezinska et al., 2015). The integration level is commonly measured by several, almost corresponding, scales (Bernardo et al., 2009). Sampaio et al. (2012) propose four evolution levels towards complete integration: documentation integration, management tools integration, common policies and goals, and common organizational structure. Integration degree can be otherwise assessed at strategic, tactical and operational level as full, partial or no integration (Asif et al., 2010b). Abad et al. (2014) classified integration into three levels depending on the IMS documentation (documental harmonisation) and the final configuration 
of the IMS process map (partial and full integration), and explored the relationship between the integration level and corporate benefits.

The "integration of systems audits" refers to the integration of both the internal and the external audits, that may result in benefits, such as the optimized use of resources (Karapetrovic and Willborn, 1998b; Douglas and Glen, 2000; Karapetrovic, 2002b; Zeng et al., 2007; Kraus and Grosskopf, 2008; Salomone, 2008) and reduction of time due to multidisciplinary auditors who have the capacity of auditing different MSs (Douglas and Glen, 2000; Kraus and Grosskopf, 2008; Simon et al., 2011). Karapetrovic and Willborn (2000) introduced a generic audit guideline based on the process approach. Bernardo et al. (2010) identify three different groups according to the level of audit integration, with the internal audits being more integrated than the external audits and the most integrated aspect being the auditors or audit team (similar results can be found in Simon et al., 2014). Inadequacy of audit methodologies is mentioned in the literature as one of the common barriers to integration (Searcy et al., 2012; Hoy and Foley, 2015). Researchers contend that auditors should not simply audit but also aid managers when integrating (Beckmerhagen et al., 2003a). Simon and Douglas (2013) compare the integration process between Spain and UK finding differences in the audits systems, similar results as Bernardo et al. (2011a) comparing Spain and Greece, in which Spain achieved higher levels of integration specially in the audit’s systems.

In addition to the abovementioned integration aspects, others have been analyzed such as benefits, being the most highlighted the costs savings, operational benefits, better external image and improved customer satisfaction (Zeng et al., 2007; Salomone, 2008; Asif et al., 2009, 2010c; Bernardo et al., 2015) while the most frequently encountered difficulties are the lack of resources and employees’ motivation (Salomone, 2008; Bernardo et al., 2012b; Gianni and Gotzamani, 2015).

Regarding the IMS evolution, Rocha et al. (2007) propose a model based on three axes that organizations can follow to ensure the future of IMS: 'ascension' (e.g., considering the ISO 9001, the IMS could “ascend” by implementing a total quality management model), ‘augmentation' (e.g., considering the ISO 9001, the ISO 10000 series adoption for the customer satisfaction "augments” 
the IMS), and 'assimilation', meaning that function- or stakeholder-specific MSs are further integrated in a single system. González et al. (2014) propose a model to calculate the costs of IMS implementation as a tool to support the decision-making process. Almeida et al. (2014) found that the critical success factors when integrating are top management involvement, availability of human and financial resources and training. Jadudová et al. (2016) analyzed the integration of stakeholders' management into the IMS. Related to the future sustainability, discussion about internalization of MSs is also increasing in relation to IMS, as more analyses are needed to demonstrate if organizations are implementing appropriately the IMS (Heras-Saizarbitoria and Boiral, 2013; Samy et al., 2015). Finally, Hernandez-Vivanco et al. (2016) found that organizations with fully IMS are more innovative (see also Simon and Yaya, 2012; Bernardo, 2014). As a summary of the research done on IMS, table 1 summarizes the qualitative studies published, as the current paper is also qualitative.

(Table 1 here)

Within and cross-country management research highlights possible contagion effects, enhance trade relationships and urges institutional and regulatory authorities to support corporate managerial efforts towards enhancing performance, market position and competitiveness at both company and sector levels. Contagion or mimetic effect explains similar behavioral patterns due to geographical or cultural proximity (Albuquerque et al., 2007) and is stressed to be fostered via internal or external pressures by relevant stakeholders, regulations and the need for improved visibility or reputation (Marimon et al., 2012; Alonso-Almeida et al., 2015). Furthermore, Clougherty and Grajek (2014) contend that corresponding-knowledge and absorptive-capacity in a country-pair yield efficient use of standards, and that bilaterally shared standards greatly enhance trade. Particularly with regard to the integration of MSs, it is emphasized that "firms that are more aware of the QMS meta-standards have a greater propensity to be certified to multiple standards”, 
and, thus enhance their ability to assimilate and exploit acquired knowledge and experience in its strategic decision-making (Masakure et al., 2011).

Thus, taking into consideration that the great majority of existing studies are considering ISO standards, mainly ISO 9001 and ISO 14001, in countries that are in the top 10 positions of certifications worldwide finding similar results, the aim of this paper is to analyze the integration process in a certification non-leading country, Greece, and propose a research roadmap to improve the competitiveness of the organizations integrating their MSs based on maintenance and future sustainability.

\section{Material and methods}

The case-study approach is used in this study in order to effectively describe and analyze the context and content of all basic aspects related to the subject under study. Contemporary case study scholars stress that nowadays scientific research shifted from the universal and the general, to the particular, the local and the timely (Ketokivi and Choi, 2014), meaning that case study approach give the authors the opportunity either to establish theories via analytical reasoning or generate questions, make statements and analyze phenomena under a specific research agenda (Voss et.al, 2002). Furthermore, Baxter and Jack (2008) underlined that "a holistic case study with embedded units only allows the researcher to understand one unique/extreme/critical case”. In this context, cross-case analysis increases the internal validity of the findings (Voss et al., 2002) by addressing research limitations, such as single respondents bias, and enabling researchers to seek for convergence of evidence (Gibbert and Rulgrok, 2010). For this purpose, five extended case studies were conducted in selected Greek organizations that were implementing, at least, two ISO MSs and particularly ISO 9001:2008 and ISO 14001:2004. The research is descriptive in nature in order to provide a better insight and understanding of the integration process and to identify general propositions regarding the observed practices (Yin, 2009). This methodology was extensively used by several authors that have studied the same subject in order to analyze the complex process of 
adoption and internalization of MSs and its impact on the organizations (Karapetrovic and Casadesús, 2009; Heras-Saizarbitoria, 2011; Simon et al., 2011; Almeida et.al., 2014; Domingues et al., 2015b, 2016). Considering that a new variable, such as the certification level of the country is analyzed, Eisenhardt (1989) was also followed to propose the research agenda.

\section{Sample and data gathering}

The selected cases are five manufacturing firms belonging to different industry sectors and of different size in terms of number of employees and annual turnover (maximum variation criteria according to Creswell, 1997). Also, the main requirement for the organizations to participate in the study was to be certified, at least, against the ISO 9001:2008 and ISO 14001:2004 standards. The five organizations were selected based on the notion that "generalizability of case studies can be increased by the strategic selection of cases” (Flyvbjerg, 2006) with the aim to gain as wide a perspective as possible (Miles and Huberman, 1994; Barratt et al., 2011; Bowler et al., 2015).

The unit of analysis in case studies is usually determined by the research questions pursued by the researchers (Yin, 2009) and can often provide the basis for a pilot survey. Our study is one of the first studies exploring the Integration of Management Systems in Greece and the selection of participating organizations was based firstly on the implementation of the two standards (ISO 9001:2008 and ISO 14001:2004) and secondly on the availability of information in order to increase “generalizability by the strategic selection of the cases” (Flyvbjerg, 2006). The authors' knowledge of the status of ISO 9001:2008 and ISO 14001:2004 certifications in Greece and their involvement in various studies related to ISO certification was a key point in deciding which organizations to be involved in this research. Furthermore, to improve cross-case analysis the authors chose these organizations in order to provide better familiarization with the phenomenon under study since they had all the criteria mentioned above.

The data gathering was carried out through extensive and in-depth interviews in all five organizations asking the organizations’ MS manager, using a semi-structured questionnaire with 
open-ended questions. Using a single respondent as a source of data gathering has many limitations; however, in our study the MS manager is the person that according to the literature can be viewed as a "change agent" within the organization, having new roles and duties and be equally involved in the overall corporate strategy. Furthermore, MS manager is a key person in MSs integration, and his/her view and perceptions of the organization's integration strategy, methodology, level, and the integration of the audits shape and determine the overall effort towards successful MS integration.

The main purpose was to collect data and produce basic information, enabling qualitative observations concerning organizations' MSs integration. Each site was written up as an integrated case study, with the focus on drawing out the commonalties of meaning and understanding each site. The authors used Pope et al. (2000)'s notion of in analyzing the respondents' data which is to "identify all the key issues, concepts, and themes by which the data can be examined and referenced”. Having that in mind, our data analysis provides some ground for generalizations, even though subjective judgments were also made from the analysis of the cases.

Interviews and visits were made in pairs and the members of the research team had a proper training in the subject under study. None of the interviews was recorded; notes were taken by two researchers and then cross-contrasted, as recommended in the literature (Maxwell, 1996). In the process of comparison between cases and inference aiming to achieve the objective, clearly exploratory, the grounded theory method was used, which integrates appropriately with the general methodology of case studies (Binder and Edwards, 2010). This is a content analysis method with a strong potential in complex social phenomena as the present one. Following a systematic process, qualitative evidence is categorized and grouped in an effort to be interpreted more easily (Glaser and Strauss, 1967). Internal validity was assured by the search for common patterns intended to explain the understanding of the phenomena under study (Voss et al., 2002; Yin, 2009), while the reliability is guaranteed with the use of structured interviews based on a pre-determined protocol to assure cross-case data collection (Yin, 2009). In-depth knowledge about each organization, as well as qualitative information from all interviewees was obtained. 
The questionnaire used was divided into three main parts: the first part was about the existing MSs in organizations under study (questions were about the implementation of each MS, the implementation reasons, advantages and disadvantages, etc.), the second part consisted of questions regarding the integration of MSs (interviewees were asked about the integration process, the level of integration, the audits, etc.) and the last part was about the organization's thoughts and actions concerning future certifications. For this research, the first two parts regarding implemented and integrated MSs are used.

\section{Management Systems Integration in Greece}

Greece is the country analyzed in this paper because it presents low levels of certifications against ISO 9001 and ISO 14001 considering the data available in recent years (see ISO, 2015), and in contrast with the countries that had been analyzed by Marimon et al. (2010) in a paper called “Certification intensity level of the leading nations in ISO 9000 and ISO 14000 standards”. In order to compare the certification level of Greece with the leading countries, the information provided by the ISO survey has been used. Two comparisons for both MSSs are presented, first the number of certificates in absolute terms and then, the number of certificates per capita (x1000).

In order to create the figures, the countries that were ranked in the top 10 list of certificates in the period of 2007-2014 were considered. Only those countries that appeared in the list in all the years were used in the comparison, adding the Greek data.

Figures 1 and 2 show the number of certificates against ISO 9001 and ISO 14001 in absolute terms. It can be observed that Greece ranks the last one, far from the leading countries.

(Figures 1 and 2 here)

Figures 3 and 4 show the number of certificates per capita (x1000) for both MSSs. In this case, although Greece is $5^{\text {th }}$ in the ranking, there are 8 countries and thus, it cannot be stated that it 
is a leading country. For the ISO 14001 it is clear that Greece is not leading the comparison as it is the last in the ranking as in the previous comparison.

(Figures 3 and 4 here)

Thus, according to this comparison, it could be stated that Greece is not a leading country in terms of ISO 9001 and ISO 14001 certifications. This is the justification for analyzing this country and comparing the integration process of Greek organizations to other countries such as Spain and UK that are leading countries in terms of certifications, as can be seen in the previous figures.

\section{Results and discussion}

The results presented are based on the comparison among cases in order to ease the interpretation and readability. In order to assure privacy and confidentiality, the names of the organizations will not be revealed. Instead, companies will be identified as C1, C2, C3, C4 and C5. All five organizations differ in size and sector except two that belonged to the same sector (food and beverages) and two of them are traditional medium to small family owned organizations. A brief description of the characteristics of each company is presented in Table 2.

For better understanding of the various aspects of the integration process in the selected organizations, the results are presented in two subsections. Firstly, the aggregated findings of the five case studies are presented and discussed and secondly, the research agenda proposal is posed.

The data analysis of the organizations under study follows the integration process' aspects, as these were presented in the literature review section. This approach gives the opportunity to acquire a better view of possible convergence, similarities, differences and overall deviations in the findings (table 2 summarized the comparison). 


\section{a) Integration strategy}

This integration aspect refers to the order and number of implemented MSs. Regarding the number (see table 2), four out of five organizations have adopted more standards than the ISO 9001 and ISO 14001 (at least three MSs each), while only one of them (company C1) had only the two required systems in place, although as the manager declared, they would like to implement more MSs in the future.

Regarding the implementation order of individual MSs, three of the companies, C2, C3 and C4, are following the most usually implemented order that is implementing first the QMS, second the EMS and then other MSs. From these three, C2 and C3 have the HSMS in the third place, while C4 has implemented the food safety MS (FSMS), ISO 22000. This result was expected, i.e. that the majority of case companies implemented first QMS and then EMS because, among other possible reasons such as the sector or exportations, ISO 9001 was launched before the ISO 14001 (see Karapetrovic and Casadesús, 2009; Bernardo et al., 2012a; for similar results on this aspect). It is noteworthy that company $\mathrm{C} 4$ has adopted the second and third standards simultaneously taking advantage of the synergies between these two systems (Karapetrovic and Willborn, 1998a; Karapetrovic, 2003; Zeng et al., 2007; Karapetrovic and Casadesús, 2009; Asif et al., 2010c). Companies C3 and C4 highlighted the implementation of sectoral MSs. Both organizations stated that the tendency is that clients and suppliers are asking for standards that are more focused on the sector characteristics.

For the two organizations following a different order, C1 and C5, both have implemented first the EMS and secondly the QMS (the second possibility proposed by Karapetrovic and Willborn, 1998a). The main reason for this order, as commented by the interviewee in company C1, was the sector in which the company operates. Chemical industries are forced by legislation and various NGO's to be more thoughtful and act responsibly on environmental issues. On the other hand, company C5 has adopted the third standard, for food safety, simultaneously with the ISO 
9001 standard. However, firm C5 does not integrate its MSs, since according to the MS manager any profit from synergies was hardly anticipated.

In our study, the ISO 22000 was the only standard that companies have adopted simultaneously with ISO 14001 and ISO 9001. This finding is attributed to the enhanced compatibility of the food safety standard with the quality and environmental standards. Hence, FSMS has no problems to be integrated with the rest of the systems implemented. In company C4, the MS manager mentioned that the ISO 9001 standard's requirements are partially integrated into ISO 22000, making the two standards completely harmonized. It is worth noting that Greece is among the top three countries worldwide in terms of number of ISO 22000 certifications, certified organizations in December 2014 (see ISO, 2015). Regarding this specific MSSs, Greece is a leading country and thus, this could mean that Greek organizations are implementing new and more sectorspecific MSSs in order to gain competitive advantage, a situation that the diffusion of MSSs literature forecasted (see e.g., Marimon et al., 2011)

\section{b) Integration methodology}

The four out of the five studied organizations have integrated their MSs at a certain level. All of them have followed the same methodology. Firstly, an analysis of the common elements of the implemented MSs was applied. All quality managers in the four organizations highlighted the difficulty of applying the process and the issues emerging of using this methodology. Secondly, the organizations have compared the standard requirements of all MSs and have adapted their own requirements to standards' requirements. There is only one difference, in company C4 they applied the analysis based on their internal procedures, not on the standards. In the interviewee's words, "we have adjusted the systems to our internal processes and try to make the standard fit for purpose”. This methodology has been seen as common in other studies, such as in Karapetrovic et al. (2006) and Bernardo et al. (2011c). 
Another common characteristic at this stage is the use of software application in order to manage effectively all implemented standards. In companies C1 and C2, they highlighted the importance of using software to integrate the systems, that ease the integration and allows them to have the systems fully integrated and it also helps in its maintenance. However, company C5 is not integrating their MSs because for them "it is difficult to integrate two separate systems that manage different aspects of a company”.

(Table 2 here)

\section{c) Integration level}

Concerning the degree of integration, three out of five companies declared having their MSs fully integrated: C1, C2 and C4. Company C3, has achieved partial integration of its MSs while C5 keeps MSs separate.

For the fully integrated MSs, managers valued it as: "the system is one" (Company C2) and "it makes it easier to manage them" (Company C4). Similar results can be found in prior research (Douglas and Glen, 2000; Karapetrovic et al., 2006; Zeng et al., 2007; Salomone, 2008; Bernardo et al., 2009; Karapetrovic and Casadesús, 2009). The level of integration of all MSs is found high, since in all organizations objectives, resources and procedures are fully integrated. However, in company $\mathrm{C} 1$, the authors noticed that there were two people managing the integrated system. According to the interviewee's comment on this, senior management assigned a manager for each MS before integration and considered more efficient to keep them both in order to cooperate in the management of the new IMS, as each one has the specific knowledge and expertise for each individual implemented system.

Another finding was that in company C3, the person responsible for the MSs revealed that his will was to integrate all the systems into one, but there were not enough resources to manage it effectively. The integrated procedures used were: training, evaluation of suppliers, internal audits, 
preventive and corrective actions and document control. Only partial integration was reached because "the function-specific part of each system makes it difficult to integrate". Another problem arisen is that senior management does not understand the necessity of institutionalizing the integration process. Finally, in company C5, top management decided not to integrate their MSs, but rather to manage some aspects of MSs and human resources management in an integrated way.

The authors in order to classify the five organizations of this study according to their level of integration used the classification approach developed by Bernardo et al. (2009). Companies C1, C2 and C4 would be in the last group, as they have fully integrated their MSs. Company C3 could be classified in the partial integration group and finally, company C5 is not in the first group, and might be grouped, timidly, in the initial partial integration cluster because some aspects are integrated. According to the interviewees’ opinions, there are two main characteristics that can lead to a successful integration process: (1) the availability of resources to apply the integration and (2) the top management commitment to consider integration as a strategic factor for the organization. If these two elements are present in the organization, the integration process ends with a fully integrated system, if not; partial or no integration is achieved.

The results in this aspect, as the answers are subjective considering the vision of one person, the one that has responsibility on the system, could lead to propose, in the future, an objective scale to measure the levels of integration of the different aspects involved in the process.

\section{d) Integration of systems' audits}

The integration level of audits has been measured considering the integration of audit team, time, process, plan and report, and results. Before explaining the cases, a brief explanation about these audits integration criteria is given. In the interview, participants were asked to say if, e.g., the auditors' team was the same for all standards (fully integrated), the same for some norms (partially integrated) or different (no integration). The levels are based on Karapetrovic (2003)'s proposed levels: partial integration and full integration. In the case of time, if the audits were conducted 
simultaneously for all norms, they were fully integrated; if they were simultaneously performed for some norms, the level was partial; and finally, if the audits were carried out with different timeframes, they were not integrated. For the rest of the criteria, the same logic is applied (the same levels are considered in Bernardo et al., 2010, 2011b; Simon et al., 2011).

Another aspect of the integration of audits should be also clarified. The integration of the internal audits is based on a decision made by the organization that is also who is performing it with its own internal auditors trained to perform the integrated internal audit. For the external audit, although the decision is also made by the organization, its performance depends on the certification bodies who should have trained and skilled auditors to perform these audits.

Only company C2 has the internal and external audits fully integrated in terms of team, time, process, plan and report, and results. For the internal audits, C1 and C2 have all the internal audit elements fully integrated. Company C4 has full integration in auditors' team and audit time, and has a single audit plan but distinct final reports. This organization is not integrating the audit time or the results, as the internal audit only detects nonconformities. In company C3 the internal audits are not integrated, only the audit plan is unified, but the final reports are different for each norm. C5 is not integrating the internal audit system.

For the external audits, companies C1, C2 and C4 do not adopt a similar approach as they do in the internal audits. The common elements are the audit time and results. The audits are done simultaneously and in all three companies the external audits suggest opportunities to improve each norm's adoption and the integrated system's implementation. Company C2 has reached full integration in all the audit elements, but companies C1 and C4 present different levels of integration. In company C1, the auditors' team is different for each norm, the systems are audited as interrelated and there is a single audit plan and a unified final report produced for all norms. In company $\mathrm{C} 4$, the auditors are the same only for some norms, the systems are audited as separated and there is a unique audit plan but a final report for each norm. Finally, in company C3 audit results suggest opportunities to improve each norm and the integrated system, but the other audit 
elements are not integrated, and C5 has the external audit team, process and results partially integrated, but the time and audit plan and final report not integrated.

These companies can also be classified into the three groups found in Bernardo et al. (2010), where companies were grouped according to the internal and external audits level of integration. Company C2 can be classified in the third cluster, as it has the highest levels of integration in both internal and external audits. The other companies integrating the audits, cannot be classified exactly, as the level of integration does not fit with the study results, but, approximately, C1, C2 and C3 could be grouped in the first cluster, as internal audits are more integrated than the external (Bernardo et al., 2010). Company C5 cannot be classified respectively, because in the study, all the Spanish organizations were integrating the audits at a certain level, and this is not the case for this company.

Comparing the level of integration of MSs and audits' systems, as mentioned, MSs are more integrated than the audits. In general, the internal audit level of integration is similar to the level of IMS, but external audits integration is not aligned (similar results are found by Bernardo et al., 2011b).

\section{Research agenda}

Case results indicate that IMS implementation and evolution in Greece is following a similar pattern as in other countries considering some aspects of the process. As in other countries, the tendency is to fully integrate the MSs, following a similar methodology and strategy, yet not the respective MS audits (Bernardo et al., 2009, 2012a; Santos et al., 2011; De Oliveira, 2013; Simon and Douglas, 2013; Almeida et al., 2014). These differences can be explained by the certification level. Although more research is needed to state this relationship, when comparing the Greek case with UK and Spain, which are leading countries, the integration process is more mature and higher levels of audits integration are achieved (Bernardo et al., 2011a; Simon and Douglas, 2013). 
The research agenda proposed in this section has the aim of motivating future research in order to reduce this gap among countries. Four main propositions are posed.

First, Greece is not leading in terms of the number of certifications to the ISO 9001 and ISO 14001 standards worldwide, and achieves lower levels of integration compared to other leading countries analyzed, at least for the auditing systems, the first proposition is the following:

P1. The integration of audits seems to be conditioned by the experience in managing MSs individually.

From another perspective, cross-case findings can be related to the IMS approach proposed by Rocha et al. (2007) integrating sustainable development principles. Drawing from the three-axial IMS expansion model over time (Rocha et al., 2007), Greek organizations tend to follow the 'assimilation' path, since - according to this research findings - they further proceed integration by adopting a sector-specific standard, i.e., the FSMS, to address the needs of the food chain stakeholders. More specifically, Greek managers, when inquired on their decision, mentioned regulatory enforcement, competitive advantage and improved market position among the main incentives for this standard's selection. It is worth noting that Greece is the third country in terms of ISO 22000 certifications worldwide (see ISO, 2015). This supports the cross-case findings, in that Greek organizations are trying to gain competitive advantage in food sector at a worldwide level (export-oriented companies), as well (Marimon et al., 2011; ISO, 2015). Furthermore, the ISO 22000 standard is compatible to the ISO 9001 standard, thus allowing Greek organizations to benefit from synergies in order to have a better position in this sector. Based on the above discussion, the second proposition for future research can be posed:

P2. The 'assimilation' path is an adequate strategy to gain competitive advantage and foster IMS maintenance and corporate sustainability. 
Related to this, in the future, measureable indicators should be gathered in order to evidence the efficiency and cost savings reported in the literature (González et al., 2014). Also, as Almeida et al. (2014) found, critical success factors should be considered for a successful maintenance of the IMS.

Longitudinal cross-case analysis is suggested to address IMS sustainability in relationship to the internalization concept. An entire research stream is dedicated on the internalization of MSs meaning the depth and width of embeddedness of MS standards principles into the everyday business operations (Heras-Saizarbitoria, 2011; Bowler et al., 2015). It is found that internalized MSs increase firms efficiency (Heras-Saizarbitoria and Boiral, 2013). However, there is a paucity of research on the impact of internalized integrated MSs on firms' performance. Based on the interviewees' point of view and prior literature indicating that IMS follows the individual MS evolution, it is anticipated that IMS internalization will bring similar benefits to the individual MS internalization. In other words, the organizations that profit from the MS advantages the most are those that have implemented MSs for internal reasons, have deeply understood the MS principles and have made the MS a routine within the organization (Heras-Saizarbitoria, 2011). Baring the above discussion in mind, the third proposition is posited:

P3. Those organizations internalizing their IMS will gain more benefits from integration than those not internalizing it.

Finally, and related to the experience in managing MSs, the last proposition is posed becoming the most general proposition:

P4: The differences in the integration of MSs between leading and non-leading countries will be minimized as the non-leading countries gain experience in managing MSs 


\section{Conclusions}

The main aim of this study is to analyze the integration process in a non-leading certification country and propose a research agenda to improve the competitiveness of the organizations integrating their MSs. Based on 5 case studies done in Greece, the following conclusions are presented.

First, according to the participants' companies, the integration of MSs has helped them in becoming more efficient and take advantage of the potential synergies of the MSs, as stressed in prior research (Karapetrovic and Willborn, 1998a; Zeng et al., 2007; Karapetrovic and Casadesús, 2009; Bernardo et al., 2015). With regard to the scope, the majority of the organizations have more than two MSs, emphasizing their trust in these systems to make them competitive in the market (Karapetrovic and Willborn, 1998a; Douglas and Glen, 2000; Karapetrovic, 2002a; Karapetrovic et al., 2006; Zeng et al., 2007; Griffith and Bhutto, 2008; Salomone, 2008; Karapetrovic and Casadesús, 2009). As far as the IMS strategy is concerned, the most frequent implementation order is adopting first the quality and then the EMS standard. In this particular research, three out of five organizations adopt the most widespread strategy, while the remaining two implement first the EMS and then the QMS (see e.g., Karapetrovic and Casadesús, 2009). This last strategy is attributed to the sector of activity. Also, 4 out of 5 organizations have implemented sectoral MSs, which help them in focusing on the sector-specific requirements (Casadesús et al., 2010; Marimon et al., 2011). This could be evidencing what has been said in previous literature that organizations decide to implement sectoral MSs to gain or increase competitive advantage.

The most common methodology used to integrate the MSs in Greek companies is the analysis of the standards' common elements, since it applies to all the case participants (as found in Karapetrovic et al., 2006; Bernardo et al., 2011c) and is also proposed in some national MSs (e.g., BSI, 2012), thus, it could be the base for ISO to propose and launch the international MSS for integration. 
Systems' audits are the weakest point in the majority of organizations in terms of integration because they have not reached the highest integration level that has been achieved in other countries. Interviewees realize that managing all systems together gives quality department the flexibility needed to revise or change various parts in both systems. However, only one company has the internal and external audits fully integrated, while the other companies have only integrated some aspects of their audits. In general, internal audits are more integrated than the external (as in Bernardo et al., 2010; Simon et al., 2011), and the most integrated aspects are audit time, plan and results. This might be attributed to the emphasis given by organizations on the allocation of resources, such as time and workload. Moreover, the lower integration level of the external audits indicates shortcomings of the Greek auditing bodies in terms of skilled IMS auditors. Another relative finding was that the certified companies were not aware of the ISO 19011:2011 standard for the audits. When inquired about the reasons, managers emphasized the lack of support and collaboration with the external auditors. This might indicate limited dissemination of supporting standards and poor communication between auditors and auditees within the country, which can be related to the Greek low certification rates.

As aforementioned, participating firms represent different sectors, sizes and ownership types, in order to allow the exploration of contingencies. However, findings did not lead to any safe conclusions on whether the size or ownership condition integration. In the present study, the only relative finding is that two out of three companies that have fully integrated their MSs are mediumsize and family-owned implying that SMEs achieve higher levels of integration, in line with prior research (De Oliveira, 2013; Abad et al., 2014). To this direction, further research is needed to substantiate the reasons behind this relationship.

Regarding the two specific research questions to be answered in this study, it could be said that the majority of the Greek organizations analyzed are integrating their MSs into an IMS, which achieved different levels of integration. The most dissimilar aspect is the audits' system, as organizations are not achieving the same level as for the IMS, and this could be, among other 
reasons, because they do not have enough experience managing certified MSSs. This is posed because countries with more experience or leading the certificates of ISO 9001 and ISO 14001, such as Spain and UK, have achieved higher levels of integration audits. However, more research is needed to extrapolate this reason in the non-leading countries.

Managerial implications are addressed to those companies that have not integrated their MSs, as integration can make them more efficient (Karapetrovic, 2003; Zeng et al., 2007, 2011) to cope with the present turmoil. Governments and certification bodies should take an initiative to help these organizations promoting the integration as a way of reducing costs and having a better understanding of both the MSs and the entire organization. Also, learning from best practices in other countries could also help in increasing the IMS implementation.

Related to this, it is important to realize a series of challenges and opportunities for research on the MSs integration process, thus, a research agenda for future studies on integration of MSs is proposed, based mainly on analyzing the relationship between experience managing individual MSs and IMS (Almeida et al., 2014), maintenance of the IMS depending on the MSs added and critical success factors (González et al., 2014) and internalization of IMS (Heras-Saizarbitoria, 2011).

This research aimed to unveil the IMS potential towards fostering the performance and competitiveness of firms operating in a country which lags in terms of ISO 9001 and ISO 14001 certifications and IMS research compared to countries where the level of both IMS research and ISO certifications is higher. However, the findings are rather narrow in scope and can hardly be considered conclusive. Future case research in more countries that, like Greece, lag in ISO certifications would yield results of wider range to be cross-analyzed and compared. Furthermore, certain sector-specific differences have emerged requiring further research within and across sectors. Resource limitations have also been underlined as impediments to integration. A resourcebased view would address these limitations and provide new insights within country specific contexts (Savino and Batbaatar, 2015). 
These limitations aside, this research contributes in addressing IMS contingencies, such as the country context in terms of an overall corporate level of IMS experience and the country's in question certification rate to function- or sector-specific standards. In this line of reasoning, integration patterns can be identified and substantiated (Wilkinson and Dale, 2001) and new IMS insights can be gained. According to Beckmerhagen et al. (2003a) "the integration of management system standards will continue to be a part of future research in the area of IMS, not only because minor differences among the standards still exist, but also because new standards that will stretch the boundaries of what we currently consider as "management systems" will appear" and, thus, the posited future research propositions are related to the research agenda towards improving the knowledge of IMS (see also Heras-Saizarbitorial and Boiral, 2013).

\section{Acknowledgments}

This article was written as part of a research project of a mobility grant financed by the Faculty of Economy and Business of the University of Barcelona.

\section{References}

Abad J., Dalmau I., Vilajosana J., (2014), Taxonomic proposal for integration levels of management systems based on empirical evidence and derived corporate benefits, Journal of Cleaner Production, 78, 164-173.

AENOR (2005), UNE 66177 Sistemas de gestión. Guía para la integración de los sistemas de gestión, Asociación Española de Normalización y Certificación, Madrid, Spain

Albuquerque P., Bronnenberg B., Corbett C., (2007), A spatiotemporal analysis of the global diffusion of ISO 9000 and ISO 14000 certification, Management Science, 53, 451-68.

Almeida J., Domingues P., Sampaio, P., (2014), Different perspectives on management systems integration, Total Quality Management \& Business Excellence, 25, 338-351 
Alonso-Almeida M.M., Marimon F., Casania F., Rodriguez-Pomeda J., (2015), Diffusion of sustainability reporting in universities: current situation and future perspectives, Journal of Cleaner Production, 106, 144-154.

Amundsen, A., (2000), Joint management of energy and environment, Journal of Cleaner Production, 8, 483-494

Asif M., Bruijn E., Fisscher O., Searcy C., Steenhuis H., (2009), Process embedded design of integrated management systems, International Journal of Quality \& Reliability Management, 26, 261-282

Asif, M., Fisscher, O.A.M., de Bruijn, E.J., Pagell, M., (2010a), An examination of strategies employed for the integration of management systems, The TQM Journal, 22, 648-669

Asif, M., Fisscher, O.A.M., de Bruijn, E.J., Pagell, M., (2010b), Integration of management systems: a methodology for operational excellence and strategic flexibility, Operations Management Research, 3, 146-160

Asif M., Joost de Bruijn E., Fisscher O., Searcy C., (2010c), Meta-management of integration of management systems, The TQM Journal, 22, 570-582

Azadeh, A., Fam, I.M., Azadeh, M.A., (2009), Integrated HSEE management systems for industry: a case study in gas refinery, Journal- Chinese Institute of Engineers, 32, 235-241

Badreddine, A., Ben Romdhane, T., Ben Amor, N., (2010), A multi-objective approach to generate an optimal management plan in an IMS-QSE, Chapter 29. In: Ao, S.I., Gelman, L. (Eds.), Electronic Engineering and Computing Technology, Lecture Notes in Electrical Engineering, 60, Springer Science p Business Media B.V, 335-347

Bamber, C.J., Sharp, J.M., Hides, M.T., (2000), Developing management systems towards integrated manufacturing: a case study perspective, Integrated Manufacturing Systems, 11, $454-461$ 
Barratt M., Choi T.Y., Li M., (2011), Qualitative case studies in operations management: Trends, research outcomes, and future research implications, Journal of Operations Management, 29, 329-342.

Baxter P., Jack S., (2008), Qualitative Case Study Methodology: Study Design and Implementation for Novice Researchers, The Qualitative Report, 13, 544-59.

Beckmerhagen I., Berg H., Karapetrovic S., Willborn W., (2003a), Integration of management systems: focus on safety in the nuclear industry, International Journal of Quality \& Reliability Management, 20, 210-228

Beckmerhagen, I.A., Berg, H.P., Karapetrovic, S.V., Willborn, W.O., (2003b), Auditing in support of the integration of management systems: a case from the nuclear industry, Managerial Auditing Journal, 18, 560-568

Bernardo M., Casadesús M., Karapetrovic S., Heras I., (2009), How integrated are environmental, quality and other standardized management systems? An empirical study, Journal of Cleaner Production, 17, 742-750

Bernardo M., Casadesús M., Karapetrovic S., Heras I., (2010), An empirical study on the integration of management system audits, Journal of Cleaner Production, 18, 486-495

Bernardo, M., Simon, A., Gotzamani, K., Casadesús, M., (2011a), La dimensión geográfica de la integración de sistemas de gestión, XI Congreso Nacional de ACEDE, Barcelona, September 2011

Bernardo M., Casadesús M., Karapetrovic S., Heras I., (2011b), Relationships between the integration of audits and management systems: An empirical study, Total Quality Management, 26, 659-672

Bernardo M., Casadesús M., Karapetrovic S., (2011c), Are methods used to integrate standardized management systems a conditioning factor of the level of integration? An empirical study, International Journal for Quality Research, 5, 213-222 
Bernardo, M., Gotzamani, K., Vouzas, F., Casadesús, M., (2011d), A qualitative study on management systems integration, 14th QMOD Conference on Quality and Service Sciences, Book of full paper, San Sebastian, Spain, 251-263

Bernardo M., Casadesús M., Karapetrovic S., Heras I., (2012a), Integration of standardized management systems: Does the implementation order matter?, International Journal of Operations \& Production Management, 32, 291-307.

Bernardo M., Casadesús M., Karapetrovic S., Heras I., (2012b), Do integration difficulties influence management system integration levels?, Journal of Cleaner Production, 21, 23-33.

Bernardo, M., Gotzamani, K., Gianni, M., (2013), Certification maturity as a diffusion factor for management systems integration, 20th EurOMA Conference - Operations Management at the Heart of the Recovery, 7-12 June, Dublin, Ireland

Bernardo, M., (2014), Integration of management systems as an innovation: a proposal for a new model, Journal of Cleaner Production, 82, 132-142.

Bernardo M., Simon A., Tarí J.J., Molina-Azorín J.F., (2015), Benefits of management systems integration: a literature review, Journal of Cleaner Production, 94, 260-267.

Binder M., Edwards J., (2010), Using grounded theory method for theory building in operations management research. A study on inter-firm relationship governance, International Journal of Operations \& Production Management, 30, 232-259

Blecken, A., Zobel, A., Maurantzas, E., (2010), Development of a lean quality management system: an integrated management system, Advanced Manufacturing and Sustainable Logistics, Lecture Notes in Business Information Processing, 46, 141-151

Bonk-Kassner, C., Ehmann, J., Gallhoff, G., Moore, D.S., Moos, B., Siegemund, B., (1997), Integration of parallel-operating quality Systems, Accreditation and Quality Assurance, 2, 285-293 
Botta S., Comoglio C., Petrosillo I., (2013), Implementing the environmental and social policies of a municipality through an integrated management system: theoretical framework and case study, Journal of Environmental Planning and Management, 56, 1073-1095

Bowler, K., Castka P., Balzarova M., (2015), Understanding firms’ approaches to voluntary certification: Evidence from multiple case studies in FSC certification, Journal of Business Ethics, DOI: 10.1007/s10551-015-2880-1.

BSI (2012), PAS 99 Specification of common management system requirements as a framework for integration, British Standards Institution, London, UK

Campos, C.A.O., Medeiros, D.D., (2009), A model for integration of management systems, Produçao, 19, 70-86

Casadesús M., Karapetrovic S., (2005), An empirical study of the benefits and costs of ISO 9001: 2000 compared to ISO 9001/2/3: 1994, Total Quality Management \& Business Excellence, 16, 105-120.

Casadesús M., Marimon F., Alonso-Almeida M., (2010), The Future of Standardised Quality Management in Tourism: Evidence from the Spanish Tourist Sector, The Service Industries Journal, 30, 2457-2474.

Chan, Y.K., Gaffney, P., Neailey, Ip, W.H., (1998), The establishment of an integrated management System - a paradigm for railway engineering management, TQM Magazine, 10, 420-424

Clougherty J.A., Grajek M., (2014), International standards and international trade: Empirical evidence from ISO 9000 diffusion, International Journal of Industrial Organization, 36, 7082.

Creswell, J.W. (1997), Qualitative inquiry and research design: choosing among five traditions, SAGE Publications, Inc., Thousand Oaks, California (US)

Crowder, M., (2013), Quality standards: integration within a bereavement environment, The TQM Journal, 25, 18-28 
De Oliveira O.J., (2013), Guidelines for the integration of certifiable management systems in industrial companies, Journal of Cleaner Production, 57, 124-133.

Domingues J.P.T., Sampaio P., Arezes P.M., (2015a), Analysis of integrated management systems from various perspectives, Total Quality Management \& Business Excellence, 26, 1311-1334. Domingues, J.P.T., Sampaio, P., Arezes, P.M., (2015b), Integrated management systems as complex adaptive systems, Proceedings of the 8th WOS.net International Conference, Porto, Portugal.

Domingues, P., Sampaio, P. and Arezes, P.M., (2016), Integrated management systems assessment: a maturity model proposal, Journal of Cleaner Production, 124, 164-174.

Douglas A., Glen D., (2000), Integrated management systems in small and medium enterprises, Total Quality Management, 11, 686-690.

Eisenhardt, K.M., (1989), Building Theories from Case Study Research. Academy of Management Review, 14, 532-550.

Flyvbjerg B., (2006), Five Misunderstandings About Case-Study Research, Qualitative Inquiry, 12, 219-245.

Fresner, J., (1998), Starting continuous improvement with a cleaner production assessment in an Austrian textile mill. Journal of Cleaner Produciton, 6, 85-91

Fresner, J., Engelhardt, G., (2004), Experiences with integrated management systems for two small companies in Austria, Journal of Cleaner Production, 12, 623-631

Garengo P., Biazzo S., (2013), From ISO quality standards to an integrated management system: an implementation process in SME, Total Quality Management and Business Excellence, 24, 310-335.

Gianni M., Gotzamani K., (2015), Management Systems integration: lessons from an abandonment case, Journal of Cleaner Production, 86, 265-276

Gianni, M., Gotzamani, K., Vouzas, F., (2016), Food integrated Management Systems: Dairy industry insights, International Journal of Quality and Reliability Management, in press 
Gibbert M., Ruigrok W., (2010), The 'what' and 'how' of case study rigor: Three strategies based on published work, Organizational Research Methods, 13, 710-737.

Glaser B., Strauss, A., (1967), The Discovery of Grounded Theory: Strategies for Qualitative Research, Nueva York: Aldine

González P., Rosario M., Lambán C., Pilar M., (2014), Costs modelling applied to activities of integrated management, Key Engineering Materials, 615, 124-129

Gotzamani K., Tsiotras G., (2002), The true motives behind ISO 9000 certification: Their effect on the overall certification benefits and long term contribution towards TQM, International Journal of Quality \& Reliability Management, 19, 151-169

Griffith A., Bhutto, K., (2008), Improving environmental performance through integrated management systems (IMS) in the UK, Management of Environmental Quality: An International Journal, 19, 565-578.

Grosskopf, J., Milliman, J., Lando, D., (2007), Using a unified risk management approach for EH\&S and security: Results of a pilot project, Environmental Quality Management, 17, 3-16

Hacham, H., Tetro, N., Kochari-Azolai, S., Stern, N., Mizrahi, D., Lisenker, A., Gazit, E., (2007), Unification of the quality assurance systems of public health laboratories conformed to ISO 17025, ISO 15189, and ISO 9000: a major organizational change, Accreditation and Quality Assurance, 12, 409-413

Heras-Saizarbitoria I., (2011), Internalization of ISO 9000: an exploratory study, Industrial Management and Data Systems, 111, 1214-1237.

Heras-Saizarbitoria I., Boiral O., (2013), ISO 9001 and ISO 14001: towards a research agenda on management system standards, International Journal of Management Reviews, 15, 47-65

Hernandez-Vivanco, A., Bernardo, M. and Cruz-Cázares, C. (2016), "Relating Open Innovation, Innovation and Management Systems Integration”, Industrial Management and Data Systems, In press 
Ho, S.K.M., (2010), Integrated lean TQM model for sustainable development, The TQM Journal, 22, 583-593

Hoy Z., Foley A., (2015), A structured approach to integrating audits to create organizational efficiencies: ISO 9001 and ISO 27001 audits, Total Quality Management \& Business Excellence, 26, 690-702

Hughes, S., Karapetrovic, S., (2006), ISO 10002 complaints handling system: a study, International Journal of Quality and Reliability Management, 23, 1158-1175

ISO, (2008), The integrated use of management system standards, International Organization for Standardization, Geneva, Switzerland

ISO, (2015), The ISO Survey of Certifications - 2014, International Organization for Standardization, Geneva, Switzerland.

Ivanova, A., Gray, J. and Sinha, K., (2014), Towards a unifying theory of management standard implementation: The case of ISO 9001/ISO 14001, International Journal of Operations \& Production Management, 34, 269-1306

Jadudová, J., Zelený, J., Hroncová Vicanová, J., Marková, I., (2016), Stakeholder management as part of integrated management system, Production Management and Engineering Sciences Scientific Publication of the International Conference on Engineering Science and Production Management, ESPM 2015, pp. 119-123

Jørgensen, T.H., (2008), Towards more sustainable management systems: through life-cycle management and integration, Journal of Cleaner Production, 16, 1071-1080

Karapetrovic S., (2002a), Strategies for the integration of management systems and standards, The TQM Magazine, 14, 61-67

Karapetrovic S., (2002b), On the concept of a universal audit of quality and environmental management systems, Corporate Social Responsibility and Environmental Management, 9, 147-156 
Karapetrovic S., (2003), Musings on integrated management systems, Measuring Business Excellence, 7, 4-13

Karapetrovic S., (2005), IMS in the M(E)SS with CSCS, Total Quality Management and Excellence, 33, 19-25

Karapetrovic S., Willborn W., (1998a), Integration of quality and environmental management systems, The TQM Magazine, 10, 204-213

Karapetrovic S., Willborn W., (1998b), Integrated audit of management systems, International Journal of Quality \& Reliability Management, 15, 694-711

Karapetrovic, S., Willborn, W., (1998c), Connecting internal management systems in service organizations, Managing Service Quality, 8, 256-271

Karapetrovic S., Willborn W., (2000), Generic audit of management systems: fundamentals, Managerial Auditing Journal, 15, 279-294.

Karapetrovic S., Casadesús M., (2009), Implementing environmental with other standardized management systems: Scope, sequence, time and integration, Journal of Cleaner Production, 17, 533-540.

Karapetrovic S., Casadesús M., Heras, I., (2006), Dynamics and integration of standardized management systems. An empirical study, Documenta Universitaria. GITASP 1, Girona, Spain

Karapetrovic S, Casadesús M, Heras-Saizarbitoria, I., (2010), What happened to the ISO 9000 lustre? An eight-year study, Total Quality Management and Business Excellence, 21, 245-267 Kauppila O., Härkönen J., Väyrynen S., (2015), Integrated HSEQ management systems: Developments and trends, International Journal for Quality Research, 9, 231-242

Ketokivi M., Choi T., (2014), Renaissance of case research as a scientific method, Journal of Operations Management, 32, 232-240 
Khanna, H.K., Laroiya, S.C., Sharma, D.D., (2010), Integrated management systems in Indian manufacturing organizations: some key findings from an empirical study, The TQM Journal, 22, 670-686

Kirkby A., (2002), The one-stop shop, Quality world, January, 2-4

Kraus J., Grosskopf J., (2008), Auditing Integrated Management Systems: Considerations and Practice Tips, Environmental Quality Management, 18, 7-16

Labodová A., (2004), Implementing integrated management systems using a risk analysis based approach, Journal of Cleaner Production, 12, 571-580

Leopoulos, V., Voulgaridou, D., Bellos, E., Kirytopoulos, K., (2010), Integrated management systems: moving from function to organisation/decision view, The TQM Journal, 22, 594-628

Llonch, M., Bernardo, M., (2016), Simultaneous integration: a case study of an SME, 2nd International Conference on Quality Engineering and Management (University of Minho, Portugal), 13-15 July 2016

López-Fresno P., (2010), Implementation of an integrated management system in an airline: a case study, The TQM Journal, 22, 629-647

Mackau, D., (2003), SME integrated management system: a proposed experiences model, TQM Magazine, 15, 43-51

Marimon F., Casadesús M., Heras I., (2010), Certification intensity level of the leading nations in ISO 9000 and ISO 14000 standards, International Journal of Quality \& Reliability Management, 27, 1002-1020.

Marimon F., Llach J., Bernardo M., (2011), Comparative analysis of diffusion of the ISO 14001 standard by sector of activity, Journal of Cleaner Production, 19, 1734-1744

Marimon F., Alonso-Almeida M., Rodríguez M., Cortez A., (2012), The worldwide diffusion of the global reporting initiative: what is the point? Journal of Cleaner Production, 20, 132-144. 
Masakure O., Cranfield J., Henson S., (2011), Factors affecting the incidence and intensity of standards certification evidence from exporting firms in Pakistan, Applied Economics, 43, 901-915.

Maxwell J., (1996), Qualitative Research Design. An Interactive Approach. Thousand Oaks, California: Sage Publications

Mezinska I., Lapina I., Mazais J., (2015), Integrated management systems towards sustainable and socially responsable organization, Total Quality Management \& Business Excellence, 26, $469-481$

Miles M.B., Huberman A.M., (1994), Qualitative data analysis, London: Sage.

Milliman, J., Grosskopf, J., Paez, O., Ayen, W., (2005), Pilot project results of an integrated security management system, Disaster Prevention and Management: An International Journal, 14 (1), 20-31

Milliman, J., Grosskopf, J., (2011), Lessons in leadership: operationalizing sustainability through an integrated management system, Environmental Quality Management, 20, 15-28

Mohannad M., Osma M.R., Yusuff R.M., Massood I., Yahya M.S., Jafil M.A.S.M., (2013), Strategies for integrating quality, environmental, safety and health management systems, Applied Mechanics and Materials, 315, 894-898

Moore, D.R.J., (2013), Sustainability, institutionalization and the duality of structure: contradiction and unintended consequences in the political context of an Australian water business, Management Accounting Research, 24, 366-386

Oskarsson, K., von Malmborg, F., (2005), Integrated management systems as a corporate response to sustainable development, Corporate Social Responsibility and Environmental Management, 12, 121-128

Pal Pandi, A., Rajendra Sethupathi, P.J., Jeyathilaga, D., (2016), The IEQMS model for augmenting quality in engineering institutions - an interpretive structural modeling approach, Total Quality Management and Business Excellence, 27, 292-308 
Pope C., Ziebland S., Mays N., (2000), Qualitative research in health care Analysing qualitative data, BMJ, 320, 114-6

Pun, K.F., Chin, K.S., Lau, H., (1999). A self-assessed quality management system based on integration of MBNQA/ISO 9000/ISO 14000, International Journal of Quality and Reliability Management, 16, 606-629

Rebelo M., Santos G., Silva R., (2014a), Conception of a flexible integrated and lean model for integrated management systems, Total Quality Management \& Business Excellence, 25, 683701

Rebelo M., Santos G., Silva R., (2014b), A generic model for integration of quality, environment and safety management systems, TQM Journal, 26, 143-159

Rebelo, M.F., Santos, G., Silva, R., (2016), Integration of management systems: towards a sustained success and development of organizations, Journal of Cleaner Production, 127, 96111

Renzi, M.F., Cappelli, L., (2000), Integration between ISO 9000 and ISO 14000: opportunities and limits, Total Quality Management, 11, 849-856

Rocha M., Searcy C., Karapetrovic S., (2007), Integrating Sustainable Development into Existing Management Systems, Total Quality Management \& Business Excellence, 18, 83-92

Rondinelli, D., Vastag, G., (2000), Panacea, common sense or just a label? The value of ISO 14001, environmental management systems, European Management Journal, 18, 499-510

Salomone R., (2008), Integrated management systems: experiences in Italian organizations, Journal of Cleaner Production, 16, 1786-1806

Sampaio P., Saraiva P., Domingues P., (2012), Management systems: integration or addition?, International Journal of Quality \& Reliability Management, 29, 402 - 424.

Samy G.M., Samy C.P., Ammasaiappan M., (2015), Integrated management systems for better environmental performance and sustainable development. A review, Environmental Engineering and Management Journal, 14, 985-1000 
Santos, M.G., Barbosa, J., Pedro, C., (2004), Integration of “QES” Systems on the Small and Medium Size Foundry Companies in Portugal. Communication Presented at the 66th Would Foundry Congress. 6-9 September, Istanbul, Turkey

Santos G., Mendes F., Barbosa J., (2011), Certification and integration of management systems: the experience of Portuguese small and medium enterprises, Journal of Cleaner Production, 19, 1965-1974.

Satolo, E.G., Calarge, F.A., Cauchick Miguel, P.A., (2013), Experience with an integrated management system in a sugar and ethanol manufacturing unit: possibilities and Limitations, Management of Environmental Quality: An International Journal, 24, 710-725

Savino M.M., Batbaatar E., (2015), Investigating the resources for Integrated Management Systems within resource-based and contingency perspective in manufacturing firms, Journal of Cleaner Production, 104, 392-402.

Searcy, C., Morali, O., Karapetrovic, S., Wichuk, K., McCartney, D., McLeod, S., Fraser, D., (2012), Challenges in implementing a functional ISO 14001 environmental management system, International Journal of Quality and Reliability Management, 29, 779-796

Simon A., Bernardo M., Karapetrovic S., Casadesús M., (2011), Integration of standardized environmental and quality management systems audits, Journal of Cleaner Production, 19, 2057-2065

Simon, A., Yaya, L.H.P., (2012), Improving innovation and customer satisfaction through systems integration, Industrial Management \& Data Systems, 112, 1026-1043.

Simon A., Douglas A. (2013), Integrating management systems: Does the location matter?, International Journal of Quality and Reliability Management, 30, 675-689

Simon, A., Yaya, L.H.P., Karapetrovic, S., Casadesús, M., (2013), An empirical analysis of the integration of internal and external management system audits, Journal of Cleaner Production, 66, 499-506 
Simon A., Yaya L.H.P., Karapetrovic S., Casadesús M., (2014), An empirical analysis of the integration of internal and external management system audits, Journal of Cleaner Production, 66, 499-506

Spilka, M., Kania, A., Nowosielski, R., (2009), Integration of management systems on the chosen example, Journal of Achievements in Materials and Manufacturing Engineering, 35, 204-210

von Ahsen, A., Funck, D., (2001), Integrated management systems - opportunities and risks for corporate environmental protection, Corporate Environmental Strategy, 8, 165-176

von Ahsen, A., (2013), The integration of quality, environmental and health and safety management by car manufacturers e a long-term empirical study, Business Strategy and the Environment, 23, 395-416

Voss C., Tsikriktsis N., Frohlich M., (2002), Case research in operations management, International Journal of Operations \& Production Management, 22, 195 - 219

Wilkinson, G., Dale, B.G., (1998a), System integration: the views and activities of certification bodies, TQM Magazine, 10, 288-292

Wilkinson, G., Dale, B.G., (1998b), Manufacturing companies' attitudes to system integration: a case study examination, Quality Engineering, 11, 249-256

Wilkinson, G., Dale, B.G., (2000), Management systems standards: the key integration issues, Proceedings of the Institution of Mechanical Engineers, Part B: Journal of Engineering Manufacture, 214, 771-778

Wilkinson G., Dale B., (2001), Integrated Management Systems: A Model Based on a Total Quality Approach, Managing Service Quality, 11, 318-330.

Williams J., (2004), The impact of motivating factors on implementation of ISO 9001:2000 registration process, Management Research News, 27, 74 - 84

World Bank (2016), World Bank, Available at: http://www.worldbank.org

Yin R., (2009), Case Study Research: Design and Methods. Thousand Oaks, California: Sage Publications 
Zeng S., Shi J., Lou G., (2007), A synergetic model for implementing an integrated management system: an empirical study in China, Journal of Cleaner Production, 15, 1760-1767

Zeng, S.X., Chun, M.T., Tam, V.W.Y., (2010), Integrating safety, environmental and quality risks for project management using a FMEA method, Engineering Economics, 21, 44-52

Zeng S., Xie X., Tam C., Shen L., (2011), An empirical examination of benefits from implementing integrated management systems (IMS), Total Quality Management \& Business Excellence, 22, $173-186$

Zutshi, A., Sohal, A.S., (2005), Integrated management system: the experiences of three Australian organisations, Journal of Manufacturing Technology Management, 16, 211-232 